\title{
Shaping the future of our training
}

\author{
${ }^{1} \mathrm{RJ}$ Hollick, ${ }^{2} \mathrm{DP}$ Ripley, ${ }^{3} \mathrm{KE}$ Walesby
}

${ }^{1}$ Chair, RCPE Trainees and Members' Committee; Clinical Research Fellow Rheumatology, University of Aberdeen \& Specialty Registrar Rheumatology, NHS Grampian; 'Vice-Chair, RCPE Trainees and Members' Committee; Cardiac MRI Clinical Research Fellow, University of Leeds \& Cardiology Registrar, Northern Deanery; 'Vice-Chair, RCPE Trainees and Members' Committee; Specialty Registrar Geriatric \& General Medicine, NHS Tayside

\begin{abstract}
The Shape of Training Review proposed fundamental changes to the nature and delivery of medical training in the UK. In part this is to respond to the increasing care needs of our ageing population and importantly to address problems within the current system of medical training. Concerns have been raised by trainees over the process and outcome of the Review, and the RCPE's Trainees \& Members' Committee has worked to ensure that the views and experiences of medical trainees from across the UK have been represented. This Perspective provides an overview of the proposals, our concerns about the process and a summary of ongoing work to address these issues.
\end{abstract}

Correspondence to $\mathbf{R}$ Hollick Royal College of Physicians of Edinburgh

9 Queen Street

Edinburgh EH2 IJQ

UK

e-mail rhollick@nhs.net

KEYWORDS Future Hospital, Medical Registrar, medical training, Trainees and Members' Committee, Shape of Training, RCPE

DECLARATION OF INTERESTS No conflict of interest declared.

\section{BACKGROUND}

\section{Changing demographics and hospital pressures}

The rising prevalence of chronic diseases presents a major challenge to the healthcare system worldwide. ${ }^{1,2}$ Advances in disease management together with an ageing population mean that two-thirds of those admitted to hospital are over 65 years of age, with a mean of 2.6 comorbidities (increasing to 3.6 in those $>85$ years). ${ }^{3,4}$ Current models of service delivery in the NHS do not meet the needs of our changing patient demographics.

At the same time, pressure in the acute specialties has intensified, exaggerated by a significant reduction in the number of acute beds with minimal evidence of increases in community care. There are one-third fewer acute and general medical beds than 25 years ago..$^{5}$ Latest data from Scotland shows this trend is continuing; between March 2010 and December 2014 the number of medical beds reduced, while discharges increased by $17 \% .3$ Throughput rose from 18 to 25 patients per bed per month.3 Compounding this are increasing problems with ensuring continuity of care, a factor reported as a significant concern by hospital doctors. ${ }^{6}$ It is not uncommon for patients to be moved more than four times during a hospital stay; each ward move adding one day to the overall length of stay and increasing risk of adverse events such as falls and delirium. ${ }^{7.8}$ In parallel, mental health issues continue to be prevalent across all ages and impact on other aspects of health. ${ }^{9}$

\section{Current problems facing medical training}

The 2012 consultant census conducted by the Federation of Royal Colleges of Physicians of the UK found that while acute medicine and geriatric medicine were the largest recruiting specialities, they had a significant shortage of trainee numbers with around $50 \%$ of advertised consultant posts unfilled. ${ }^{10}$ This is mirrored in recent Scottish data for entry into specialty training and many positions remain unfilled at consultant and trainee level."

Particular difficulties are experienced in the role of the Medical Registrar, which continues to prove challenging due to the intensity and demands of the role and the often poor work/life balance. ${ }^{12-14}$ Among Core Medical Trainee (CMT) doctors, a survey conducted by the Royal College of Physicians of London (RCPL) found that only $53 \%$ of respondents felt prepared for the role of medical registrar, despite $91 \%$ spending $\geq 80 \%$ of their time on service provision. ${ }^{15}$ Tension between service provision and training, along with poor rota design and planning is recognised and must be resolved.

\section{THE SHAPE OF TRAINING REVIEW}

The Tooke Report and the Future Hospital Commission identified problems with both the future delivery of care to an increasingly older population, and problems with the current medical training model. ${ }^{2,16}$ The Shape of Training Review, ${ }^{17}$ chaired by Professor David Greenaway, was an independent review of postgraduate medical education and training. The aim was to ensure 
postgraduate medical training meets the future needs of patients and health services while training medical staff effectively to provide safe patient care.

The report set out a framework for delivering change and has been broadly supported by Health Ministers of the four home countries. Key areas included:

- producing more doctors capable of providing general care in broad specialties across a range of different settings

- adapting postgraduate training to deliver general care in broad specialties

- opportunities to 'credential' in specific areas after attaining a consultant position (driven by local workforce and patient needs)

- addressing academic training pathways

- moving full registration from the end of the first foundation year to the point of graduation from medical school (subsequently removed from Shape of Training)

Stakeholder workshops were held in October 2014 to add detail to the proposals and a report was produced for the Health Ministers of the four home countries, who subsequently released a statement in response to the Shape of Training Review in January 2015. This statement suggested focused activity aimed at key target areas; how doctors' training can be made more generic to better meet the current and future needs of patients; Staff Grade, Specialty and Associate Specialist doctors; credentialing; and the interface between primary and secondary care. The Shape of Training Steering Group will have overarching responsibility for this, with its membership expanded to include trainee representatives. Moving the point of registration will now be considered separately.

\section{THE ROLE OF THE RCPE TRAINEE AND MEMBERS' COMMITTEE IN THE SHAPE OF TRAINING REVIEW}

\section{The RCPE Trainees and Members' Committee}

The RCPE Trainees and Members' Committee (T\&MC) is an elected body which represents over 3000 trainees and members in the UK and oversees the delivery of an educational programme for trainee doctors.

In recent years the T\&MC produced the influential RCPE Charter for Medical Training, which was the foundation for the Academy Trainee Doctors' Group (ATDG) charter The Value of the Doctor in Training. ${ }^{18,19}$ This, in turn, has been incorporated into the new General Medical Council Standards for Medical Education and Training. The committee were also influential in ensuring a period of shadowing for new doctors to minimise the adverse impact of the training grade job changeover (occurring every August in the UK) on training and patient care.

Most recently we have provided a strong and influential voice representing trainee views to the Shape of Training Review. We have participated constructively with the Review process from inception and provided written and oral evidence, as well as trainee representation at stakeholder workshops. Our activities have been informed by the views of our Trainees \& Members' Online Survey Panel, ongoing dialogue with our members and will be informed further by a joint survey to be distributed to all physician trainees in association with our sister Colleges in Glasgow and London. Acting upon the concerns of our members, we have produced several statements, individually and collectively, which we led through the Scottish and UK ATDG, in conjunction with trainees' committees from sister Colleges. ${ }^{20-22}$ We have engaged with key stakeholders directly, including health ministers in England, Northern Ireland, Scotland and Wales. While our activities have focused primarily on the effects of the proposals on physicians and medical training, a number of other trainee groups have also been active and expressed concern about various aspects of the proposals. ${ }^{23}$

\section{OUR CONCERNS ABOUT THE SHAPE OF TRAINING PROPOSALS}

Some aspects of Shape of Training are welcomed broad-based training programmes in the early years of training, apprenticeship-based training, transferable competencies and greater flexibility. However, the proposals will not resolve many of the current problems. Rushing to implement and getting this wrong will have a disastrous impact on future recruitment of doctors, and therefore patient care. There is little evidence to support the case for yet more radical restructuring and we must not forget the lessons of the Modernising Medical Careers programme in the UK, which was implemented without heed of concerns, a staged transition process or significant trainee engagement. ${ }^{15,24}$ Many parts of the system could be improved without the need for radical restructuring and all new changes must be properly piloted and independently evaluated.

Excellent training ensures high quality and safe care for our patients. In order to achieve this it is essential to:

- $\quad$ Train doctors capable of delivering high quality patient care Managing risk and uncertainty are key skills for all doctors. Developing these skills requires both training and experience. Future Certificate of Specialty Training holders must have the equivalent in training and experience to current Certificate of Completion of Training holders; a Certificate of Specialty Training must not be perceived as a lesser qualification. We do not believe it would be possible 
for trainee doctors to acquire the necessary skills and knowledge to practice competently and safely in a shorter period of time than is currently mandated. Most specialities already practise with an excessive and potentially unsafe workload; advances in technology and increasing healthcare needs will necessitate an expansion in the number of specialists in parallel with an expansion in the number of doctors with more generalist skills.

- Ensure workforce sustainability Unscheduled care is challenging and stressful and is not best served by tired and demoralised doctors. Sustainability must be built into any new proposals in order to attract and retain the best doctors. Medicine must be seen as an attractive career pathway.

- $\quad$ Phased approach to implementation It is essential that any proposals to alter training be fully evaluated, with evidence to demonstrate that they will improve patient care. We advocate pilot studies and gradual change as opposed to a 'big bang'. It is vital that we learn from existing examples of evolutionary and effective practice, e.g. the well-established links between primary and secondary care in diabetes and care of the elderly.

- Avoid creation of a two-tier training system Significant unanswered questions remain in terms of access, quality control, funding and the development and delivery of credentials. These need to be definitively addressed before radical changes are implemented. Credentialing must not be used as a lever to shorten training and create a two-tier system; instead it must be linked to the delivery of high quality, safe patient care with robust mechanisms for quality assurance.

- Ensure stability and security for existing trainees Significant unresolved issues remain around the transition period for current trainees into the new system. Any changes to the current system of medical training must be phased in to avoid destabilisation of the medical workforce and compromise of patient care; stability and security are vital for existing trainees to avoid exacerbation of the current recruitment crisis.

\section{MOVING FORWARD}

\section{Shape of Training}

The Shape of Training report proposes significant changes to the way doctors are trained. Many of the unintended consequences of the Modernising Medical Careers programme arose from rapid implementation and lack of proper debate. We aim to: represent the views of our members via the Shape of Training Steering Group, minimise the impact of any changes on current trainees, and maintain stability, support and up-to-date careers advice for prospective students, undergraduates and existing trainees.
While the debate continues, there is a real risk of inertia which will only serve to worsen recruitment problems and lower morale further amongst trainees. There is a need to improve training and support for CMTs and the Medical Registrar now.

\section{Core Medical Training}

Responding to the RCPL CMT survey results, the RCPE T\&MC proposed a series of practical solutions which we fed back to the Joint Royal Colleges of Physicians' Training Board. This contributed to the development of the Core Medical Training Quality Criteria, launched in February 2015. ${ }^{25}$ These aim to improve the educational experience for trainees and drive quality, ensuring CMTs gain the required experience and confidence to perform the medical registrar role. I5 CMT-specific questions will be included on the Quality Criteria in the next General Medical Council Trainees' Survey to follow up this work.

\section{Improving the Medical Registrar role}

The T\&MC has worked closely with Dr Nicki Colledge, immediate past Director of Education and Training at the $\mathrm{RCPE}$, to lead work on Improving the Medical Registrar Role. 12 We will join the working group, chaired by Sir lan Gilmore, to facilitate translation of this important piece of work into action across the four nations of the UK.

Securing a sustainable medical workforce is essential to ensuring we provide high quality care to our patients. Excellent training equals excellent patient care, and it is essential that trainees have a voice in the future shape of their training. 


\section{REFERENCES}

I Global status report on noncommunicable diseases 2010. World Health Organization; 2010. http://www.who.int/nmh/publications/ ncd_report20I0/en/ (accessed 23/3/20I5).

2 Future hospital: Caring for medical patients. A report from the Future Hospital Commission to the Royal College of Physicians. Royal College of Physicians; 2013. https://www.rcplondon.ac.uk/sites/default/ files/future-hospital-commission-report 0.pdf (accessed I6/4/20I5).

3 Hospital Episode Statistics. Leeds: Health \& Social Care Information Centre. www.hesonline.nhs.uk/Ease/servlet/ ContentServer?sitelD=1937 (accessed 23/3/20I5).

4 Barnett K, Mercer SW, Norbury $M$ et al. Epidemiology of multimorbidity and implications for health care, research, and medical education: a cross-sectional study. Lancet 20I2; 380: 37-43. http://dx.doi.org/I0.I0I6/S0 I40-6736(I2)60240-2

5 Imison C, Poteliakhoff E, Thompson J. Older people and emergency bed use. Exploring variation. London:The King's Fund; 2012. http:// www.kingsfund.org.uk/sites/files/kf/field/field_publication_file/ older-people-and-emergency-bed-use-aug-20I2.pdf (accessed 16/4/2015).

6 Results of RCP Health and Social Care Bill survey. London: Royal College of Physicians; 2012. https://www.rcplondon.ac.uk/pressreleases/results-rcp-health-and-social-care-bill-survey (accessed 16/4/2015)

7 Hospitals on the edge? The time for action. London: Royal College of Physicians; 20I2. https://www.rcplondon.ac.uk/sites/default/files/ documents/hospitals-on-the-edge-report.pdf (accessed 24/3/20I5).

8 McMurdo ME, Witham MD. Unnecessary ward moves. Age Ageing 2013; 42: 555-6. http://dx.doi.org// 0.1093/ageing/aft079

9 Key facts and trends in mental health: 2014 update. NHS Confederation, January 2014 http://www.nhsconfed.org/ resources/20I4/0I/key-facts-and-trends-in-mental-health---20I4update (accessed 5/6/20I5).

10 Federation of the Royal Colleges of Physicians of the UK. Census of medical registrars in the UK 20II-2012: data and commentary. London: Royal College of Physicians; 2013. https://www.rcplondon. ac.uk/sites/default/files/20II_census_-_registrar_census_-intro and rl-r20.pdf (accessed 16/4/20I5).

II Specialty Trainee Numbers 2014 - Response from the Royal College of Physicians Edinburgh. Royal College of Physicians Edinburgh; 2013. https://www.rcpe.ac.uk/sites/default/files/policy-responses/ reshaping-the-medical-workforce-in-scotland-rcpe-response.pdf (accessed 16/4/20I5).

12 Bell D, Patrick A, Hollick R et al. The Medical Registrar Role Restoring its Status and Job Satisfaction. Edinburgh: Royal College of Physicians Edinburgh; 2014. https://www.rcpe.ac.uk/sites/default/ files/medical-registrar-statement-sepl4-v2.pdf (accessed I4/4/2015)

I3 Acute care toolkit 8: The medical registrar on call: Maximising clinical experience, training and patient care. London: Royal College of Physicians London; 20I3. https://www.rcplondon.ac.uk/sites/ default/files/act8_registrars.pdf (accessed 16/4/20I5).

14 Chaudhuri E, Mason NC, Logan S et al. The medical registrar. Empowering the unsung heroes of patient care. London: Royal College of Physicians; 2013. https://www.rcplondon.ac.uk/sites/ default/files/future-medical-registrar_I.pdf (accessed I6/4/20I5)
15 Tasker F, Newberry N, Burr B et al. Survey of core medical trainees in the United Kingdom 2013 - inconsistencies in training experience and competing with service demands. Clin Med 2014; 14: |49-56. http://dx.doi.org// 0.786 I/clinmedicine. I4-2-I49

16 Tooke J, Ashtiany S, Carter D et al. Aspiring to excellence - Final Report of the Independent Inquiry into Modernising Medical Careers. London: MMC Inquiry; 2008. http://www.asit.org/assets/ documents/MMC_FINAL_REPORT_REVD_4jan.pdf (accessed 16/4/2015).

17 Greenaway D. Securing the future of excellent patient care. Shape of Training;20I3.http://www.shapeoftraining.co.uk/static/documents/ content/Shape_of_training_FINAL_Report.pdf_53977887.pdt (accessed 23/3/2015)

18 Charter for Medical Training. Edinburgh: Royal College of Physicians; 20I I. http://www.rcpe.ac.uk/sites/default/files/files/rcpe-charterfor-medical-training.pdf (accessed I5/4/20I5).

I9 A Charter for Postgraduate Medical Training: Value of the Doctor in Training. Academy of Medical Royal Colleges; 2014. http://www. aomrc.org.uk/doc_view/9750-a-charter-for-doctors-in-trainingvalue-of-the-doctor-in-training (accessed I6/4/20I5).

20 Mountford C, Slater M. The Royal College of Physicians of Edinburgh Trainees and Members' committee (RCPE T\&MC) Response to the 'Shape of Training' review call for evidence. Edinburgh: Royal College of Physicians; 20I3. http://www.rcpe.ac.uk/sites/default/files/ policy-responses/rcpe-tandmc-response-to-shape-of-trainingreview.pd1 (accessed I5/4/20I5).

2 I Hollick R. RCPE Trainees' comment on Shape of Training Report parallel expansion of general and specialty medicine required. Edinburgh: Royal College of Physicians; 2013. http://www.rcpe. ac.uk/press-release/rcpe-trainees\%E2\%80\%99-comment-shapetraining-report-parallel-expansion-general-and-specialty (accessed 15/4/20|5).

22 Hollick R, Vesey A, Dobson R et al. Joint Trainees' statement on Shape of Training. Trainees' committees of RCPE, RCPSG, RCPL, RCSE and SATDG; 20I4. http://www.rcpe.ac.uk/sites/default/files/ joint_trainees_statement_on_shape_of_training_3II0I4_final. pdf (accessed I5/4/20I5)

23 Statement on Shape of Training, British Medical Association Junior Doctors' Committee, January 2015. https://communities.bma.org. uk/my_working_life/b/weblog/archive/20I5/0I/08/response-tothe-shape-of-training-review-39-an-unprecedented-show-ofprofessional-unity-39 (accessed 5/6/20I5).

24 Walshe K. Reorganisation of the NHS in England. BMJ 2010; 341 :c 3843. http://dx.doi.org/I0.I I 36/bmj.c3843

25 Quality criteria for core medical training (CMT).JRCPTB; 20I5. http:// www.jrcptb.org.uk/sites/default/files/07II_JRCPTB_CMT_ A4_4pP_WEB.pdf (accessed I4/4/20I5). 